\title{
Influences of Mobile Phones-Based Short-Message-Services Communications on the HIV Sexual Risk Behaviors among Pregnant Women's Male Partners, Case Control Study Tanzania
}

\author{
Daudi Manyanga ${ }^{1,2 *}$, Harrieth Mtae1, Isah Mohamed Bello², Raphael Sangeda ${ }^{3}$ \\ ${ }^{1}$ Faculty of Arts and Social Sciences, Open University of Tanzania, Dar es Salaam, Tanzania \\ ${ }^{2}$ Immunization and Vaccines Development, WHO, Intercountry Support Team, Harare, Zimbabwe \\ ${ }^{3}$ Department of Pharmaceutical Microbiology, Muhimbili University of Health and Allied Science, Dar es Salaam, Tanzania \\ Email: *dpmanyanga@yahoo.co.uk, *manyangad@who.int
}

How to cite this paper: Manyanga, D., Mtae, H., Bello, I. M., \& Sangeda, R. (2020). Influences of Mobile Phones-Based ShortMessage-Services Communications on the HIV Sexual Risk Behaviors among Pregnant Women's Male Partners, Case Control Study Tanzania. Open Journal of Social Sciences, 8, 352-368.

https://doi.org/10.4236/jss.2020.86027

Received: May 14, 2020

Accepted: June 14, 2020

Published: June 17, 2020

Copyright $\odot 2020$ by author(s) and Scientific Research Publishing Inc. This work is licensed under the Creative Commons Attribution International License (CC BY 4.0).

http://creativecommons.org/licenses/by/4.0/ (c) (i) Open Access

\begin{abstract}
Introduction: In the twenty-first century, Human Immunodeficiency Virus (HIV) continues to be among the major public health problem globally. The disease is implicated to the result of the over 32 million deaths, and in 2018 the disease caused over 770,000 deaths globally. The disease can be transmitted from an HIV-positive pregnant woman to her child during pregnancy and childbirth about $15 \%-20 \%$, and $5 \%-15 \%$ in breastfeeding. Awareness of HIV infection sexual risk behaviors and practices among male partners of pregnant mothers, therefore, plays a greater role in reducing new infection to them and the prevention of mother-to-child transmission of HIV. Methods: We conducted a retrospective case-control study involving randomly selected 314 pregnant women's male partners attending PMTCT services in the Tabora Municipality for from September 2018 to August 2019. The enrolled study participants were randomly allocated to cases and controls and, SMS communication was sent twice weekly with 5 standard key messages from the PMTCT community guide and followed up. Results: The awareness that HIV infected mothers can transmit HIV infection in labor and during breastfeeding among their male partners was raised to $73.3 \%$ and $61.8 \%$ from $55.4 \%$ and $47.5 \%$ to study and control groups respectively following intervention. Similarly, men aged below 35 years from the study group showed an $18.3 \%$ change and a $35.4 \%$ change for those who were over 35 years old compared to the control. The difference was tested and found to be statistically significant with a $p$-value of 0.001 (relative risk of 0.11 ) and less than 0.001 (relative risk of 0.07 ) respectively at a $95 \%$ confidence interval. This indicates that following
\end{abstract}


SMS communication intervention men from the study group were less likely to practice HIV infection sexual risk behavior compared to the control group.

\section{Keywords}

HIV Infection Sexual Risk Behaviors, Male Partners of Pregnant Women, Short-Message-Services, PMTCT, Tabora, Tanzania

\section{Introduction}

In 2018, the Joint United Nations Programme on HIV/AIDS (UNADS) estimated that over 37.9 million people were living with Human Immunodeficiency Virus (HIV) and two-third of them were in the WHO African region indicating approximately 1 in every 25 people (UNAIDS, 2016, 2019). The HIV remained to be a global public health interest disease that contributed to over 770,000 deaths globally in 2018 .

The UNAIDS set a target of 90 - 90 by 2030 referring that $90 \%$ of people should know their HIV status and 90\% should be able to receive and use Antiretroviral therapy (ART). Studies indicate sub-Saharan Africa reached only 54\%, due to several challenges towards reaching the target (Alary et al., 2017; Bain, Nkoke, \& Noubiap, 2017). The Tanzania HIV survey in 2017 revealed that the HIV incidence for adults aged 15 - 64 years in the country was at $0.29 \%(0.40 \%$ for women and $0.17 \%$ for males) which represents about 81,000 new infections (URT, 2018).

Subnational variation in HIV prevalence exists, as it was also reported that the HIV prevalence for Njombe was $11.4 \%$ while it was $0.3 \%$ for Lindi. In the Tabora region, the HIV prevalence was 5.1\% [95\% CI (4.2 - 6)]. The viral load suppression among adults People Living With HIV/AIDs (PLWHA) is shown to be ranging from $66.8 \%$ in Kilimanjaro (high) to $29.1 \%$ in Arusha (low), and the viral suppression level in Tabora stands at 41.2\% [0.6\% - 51.7\%, 95\% CI] (URT, 2018). Community surveys and studies are indicating high HIV prevalence compared to the National average, for example, female fisherfolks were found to have a prevalence of $14 \%$ (Kapesa et al., 2018).

The risk of people including male partners of pregnant women in getting HIV varies according to several risk factors including the type of exposure and behaviors. The Centre of Disease Control and Prevention (CDC) estimates in every 10,000 exposures, the risks of infection are high for blood transfusion (93\%), receptive anal-intercourse (1.4\%), and sharing needle-sharing for the drug addicts (0.6\%). Matiko et al. conducted a study involving 408 people who inject drugs (PWID) in Tanzania and found out a prevalence of 11.3\% for PWID in 2012 (CDC, 2014; Matiko et al., 2015). Nevertheless, a different similar study conducted in Mwanza indicated that the risks of HIV infection to PWID were mainly associated with their unsafe sex behaviors rather than expected parenteral transmission (CDC, 2014). Shayo et al. conducted a study in 2017 that re- 
ported that female and male anal sex is less practiced in the 5 districts with high HIV prevalence in Tanzania and therefore maybe that behavior is less common in the country (Shayo et al., 2017).

A study involving 384 men and 384 females was conducted in Buea District, Cameroun indicated that only $41.3 \%$ of male partners of pregnant women participated in PMTCT services and $74.3 \%$ of the study participants had multiple sexual partners, and the majority $(74.8 \%)$ of those with multiple partners were not using condoms (Shey Nsagha, Edie Halle-Ekane, Shei Nfor, Ngowe Ngowe, \& Tatchwanglie Nasah, 2014). The study revealed how male participants were performing HIV risk behavior which will further infect pregnant women and expected babies with the HIV infection. Another study conducted in South Africa involving 463 male partners alluded to the association between the male partner's involvement in PMTCT services and their HIV risk behaviors practices. The results of qualitative analysis in that study elucidated that men who were participated in PMTCT services actively were less likely to conduct HIV sexual risk behaviors (MoHCDEC, 2018). These findings are similar to what was shown in the review of PMTCT and in a study in Mwanza where low participation of male partners to ANC and PMTCT services resulted into the increased risk to pregnant women who screened negative for HIV infection (Kashitala et al., 2015; Mmbaga, Kishimba, Mohammed, \& Elias, 2017).

A study by Moses et al. conducted in Nigeria involving 172 and revealed that among the participants, $44.2 \%$ were believing that HIV to be God's punishment and $3.5 \%$ believes that, the disease is of witchcraft origin (Moses, Chama, Udo, \& Omotora, 2009). In that study, $12.8 \%$ of the study participants believed that HIV cannot be transmitted if withdrawal before ejaculation practices is being done during sexual intercourse, and $19.8 \%$ believed that, taking antibiotics after sexual intercourse prevents HIV infection. This study further indicates how appropriate awareness can reduce HIV infection to pregnant women and their expected babies.

Another qualitative study conducted in Malamulo Seventh Day Adventist hospital in Malawi alluded that, the high prevalence among women in the rural areas of Malawi was contributed by multiple sexual partners of either pregnant women or their male partners (Kasenga, 2010). In African communities, studies have shown that multiple partners have resulted from polygamy's cultural legacy and uncontrollable sexual urges among men (Agnarson, Strömdahl, Levira, Masanja, \& Thorson, 2015; Shelton, 2009). The type of behavior and practices were also anticipated to exist in Tabora Municipality where the dominating tribes are Nyamwezi and Sukuma tribes exercising patriarchal values.

In South Africa, a study was conducted with 633 participants who had 1,051 partners, and it was revealed that there was a behavior for men who were introduced by their friends to young women who became their sexual partners regardless of their marital status (Fearon et al., 2019). In the same study, it was also shown that most of the old sexual partners out of their marriage were old friends. This study was a continuation of a study done before conducted by Jewkes et al. (2006) with an enrollment of 1275 volunteers which indicated that 
enrolled study participants with 3 or more sexual partners in past years were two times likely to be HIV infected (OR 2.39, 95\% CI ranged from 1.48 to 3.85 ) (Jewkes et al., 2006).

Several studies have shown that well-structured SMS can be used to raise skills among people and adopt better health behaviors. A study enrolled 927 obese adults in Korea was conducted by Faghanipour et al. who were receiving SMS on dietary, health exercise and behavior modification once a week for 12 weeks (Faghanipour, Hajikazemi, Nikpour, Shariatpanahi, \& Hosseini, 2013). In the study period, most majority of participants lost an average of $1.6 \mathrm{~kg}$. The mobilehealth (m-Health) strategy in Tanzania is implemented to improve population health in line with the opportunity of mobile phone networking expansion towards implementing World Health Agenda 71 resolutions of March 2018 (WHO, 2018). This study used the platform to test the impact of raised awareness using SMS texting on safe health practices to prevent HIV infection among pregnant women's male partners in Tabora Municipality.

Hurling et al. conducted a randomized control trial on 77 normal overweight adults and deploying the theory of planned behavior using SMS health messages (Ajzen, 2011; Hurling et al., 2007). In this study, the intervention group received the solutions to plan weekly exercise sessions with the mobile phone of perceived barriers and reminders through emails. The study revealed that, there were an increase in the higher level of moderate physical exercise to study group when compared to the controls (study group: $-2.18, \mathrm{SD}=0.59$; control group: -0.17 , $\mathrm{SD}=0.81 ; P=0.04)$. It is therefore evidenced that, SMS communications to pregnant women's male partners may increase their skills, ideation as well as reinforced to change their HIV risk behaviors (Ajzen, 1985, 2011). The behavioral decision-making process related to these behavioral theories depends on the perceived risk, probability of a loss, and the importance of a loss. These behavioral change theories are insisting the confidence in making an intention to change or in undergoing the stages of behavior change as key factors for changes to happen (Ajzen, 2011). In our study, we explored the importance of using technology (SMS messaging) to hasten the behavior change process.

There was low awareness of male partners of pregnant mothers to HIV risk behaviors in the Tabora Municipality this contributes to increased risk of mother-to-child transmission of HIV after being infected by male partners (URT, 2017, 2018). It was also viewed on the notion that, among African society perception that, child care is the primary role of a mother in contrary to the Convention on the Rights of the Child (UN, 1989).

\section{Methods}

A retrospective case-control study comparative study was conducted on knowledge, awareness, and practice among pregnant women's male partners attending the Prevention of Mother to Child Transmission (PMTCT) services in the Tabora Municipality for the period from September 2018 to August 2019. The messages used in this study were obtained from the PMTCT and HIV commu- 
nity poster and guide HIV Prevention guide, which is used by both National Aids Control and PMTCT Programmes of the Ministry of health, community development, gender, elderly and children in Tanzania. The five-key message was selected and constantly shared by one trained research assistant twice weekly for a period of 1 to 12 months based on the time of enrollment and stage of the pregnant women. The messages were in Kiswahili and were pre-tested in Ante-Natal Care (ANC) clinics before being used. The letter of clearance to conduct the research was obtained from the Open University of Tanzania and permission to carry out the research was granted after the successful submission of the letter to the Municipality Director.

The following were the selected five-key messages which were communicated twice weekly to enrolled men partners of pregnant women:

1) AIDS is caused by HIV. AIDS can be prevented and there are medicines to help PLWHA but there is no cure.

2) HIV can be transmitted in the following ways:

- Having unprotected sex with an HIV infected person (not using condoms), this includes vaginal or anal sex.

- From an HIV-infected mother to a baby during pregnancy, childbirth or breastfeeding who are not taking ARVs

3) Attend with your spouse at ANC/PMTCT clinics to get information from health workers

4) Get HIV counseling and testing with your partner

5) Make sure your spouse/pregnant mother is delivering at a health facility

Specific messages communicated (entire package in 5 SMS) in Swahili language as follows:

1) Ugonjwa wa UKIMWI husababishwa na Virusi vya Ukimwi (VVU), ugonjwa huu hauna tiba ila una kinga na kuna dawa za kusaidia wagojwa wa UKIMWI.

2) Watu wanaweza kuambukizwa VVU kwa njia zifuatazo:

- kufanya ngono bila kinga na mtu aliyeambukizwa VVU (bila kutumia kondomu); ngono ya kupitia ukeni ama kinyume na maumbile.

- Kutoka kwa mama aliyeambukizwa VVU kwenda kwa mtoto wakati wa ujauzito, kujifungua au kunyonyesha

3) Hudhuria pamoja na mwenzi wako katika kliniki ya afya ya uzazi na mtoto kupata maelezo ya waataalamu wa afya

4) Pata ushauri nasaha na pima VVU wewe na mwenzi wako

5) Hakikisha mwenzi wako anajifungulia katika kituo cha huduma za afya

\subsection{Enrolment of Study Participants, Sample Size Estimation, and Study Participants}

Probability sampling was used to enroll participants in this study using the list of PMTCT pregnant mothers' attendee's phone numbers in Tabora Municipality health facilities as a sampling frame. The cases and control were then randomly selected by the computer using numerical control. Both selected cases and con- 
trols were called and asked for the consent of whether would prefer to continue with the study or not. The study participants were requested to provide their male partners' numbers who were also asked for consent. All enrolled participants in the study were free to discontinue at any point from the study. All data were collected and uploaded on the online Open Data Kit formatted questionnaires in mobile phones.

A sampling formula of the National Institute for Health Research (NIHR), was used and a sample size of 144 was obtained after assuming standard error of 2.55, PMTCT attendance coverage of $90 \%$ and $5 \%$ precision margins (Fox, Hunn, Fox, \& Hunn, 2009). Also, non-probability sampling (convenient sampling) was used in the enrolment of the 42 informants for the in-depth interview of which 32 were service providers and Municipality supervisors. The study had two arms, the test/cases/study group and the controls, therefore a sample size of 144 study participants was deployed for both arms, and 42 participants for in-depth interviews.

The pregnant women's male partners residing in Tabora Municipality who attended ANC/PMTCT services in the Municipality between 1 September 2018 to 31 August 2019 and received SMS key community communication messages on PMTCT/HIV were regarded as cases for the study. On the other hand, controls were the pregnant women's male partners residing in Tabora Municipality who attended ANC/PMTCT services in the Municipality between 1 September 2018 to 31 August 2019 and did not receive SMS key community communication messages on PMTCT/HIV.

\subsection{Study Procedures and Data Analysis}

This study involved 314 male participants who were randomly enrolled and of which 157 men received SMS of 5 key messages for PMTCT/HIV obtained from the PMTCT and HIV community guidelines. We collected data from the online questionnaires administered to both cases and controls by 5 trained research assistants using the Open Data Kit (ODK) platform. The principle researcher monitored regularly through observing the geocoordinates of data collections and through physical supportive supervision. Also, a supervisor was deployed to monitor physically research assistants.

All collated data were validated and cleaned to remove data duplicates and or missing data for the important variables before analysis. High-quality data generated were subjected to the analysis to assess the impact of communicated SMS on the knowledge, awareness, and practices for the cases and the control groups. Descriptive analysis of the enrolled participants was made on their demographic characteristics such including age, socioeconomic status, and education. Statistical analyses were performed using Stata software (StataCorp, College Station, TX, USA, version 12) and $p$-values $<0.05$ were considered significant.

Human immunodeficiency infection sexual risks practices were measure from respondents' sexual acts. Sexual acts were rated on two response options: 1 score 
for unsafe sexual acts and 0 score for safe sexual acts. Final scores ranged from 0 to 7 , with high scores suggesting more unsafe practice on HIV infection sexual risks. The scores were measured before and after sending out SMS to the study group. The scores were gathered into two main categories such that unsafe sexual practice (score ranged from 4 to 7 ) and safe sexual practice (score ranged from 0 to 3). Assessment of the association between HIV infection sexual risks practice and exposure variables was done to both the study and the control groups before and after SMS communication by obtaining the proportion of unsafe sexual practice by exposure variables. Cross tabulation was performed to determine the proportion of unsafe sexual practice by exposure variables. Comparisons between the two study groups were done and tested for statistical significance with $\chi^{2}$ tests and Fisher exact test for categorical variables. The Relative Risk (RR) and 95\% confidence intervals were calculated to determine the risk, or likelihood, of practicing unsafe HIV infection-prone sexual acts and being in the SMS communicated group as compared to control arm.

\section{Results}

The study enrolled 314 men partners of pregnant women reflecting $109 \%$ of the expected 288 study participants who were randomly selected and distributed to cases and control groups. The age of cases ranges from 21 to 61 years with a mean of 37.4 years whereas the age for controls ranges from 18 to 58 years with a mean age of 32.1 years. The median age group for cases and controls was 35 to 44 years and 25 to 34 years age groups respectively. There is no statistical significance for age variability between the cases and control, a $p$-value is $=0.99(95 \%$ ranges from -7.98 to -2.61 ). Most of enrolled male partners of pregnant women were aged between 15 to 54 years, $90.4 \%$ for cases and $95.6 \%$ for the control group as shown in Table 1.

The study indicated that $94.3 \%$ of the participants enrolled as study groups were married and $83.5 \%$ of controls were also married. For those who were single and never married to the time of the study were $3.8 \%$ of the cases and $10.8 \%$ of the control group. Some men of pregnant women enrolled in this study had extramarital affairs. The study alluded that, majority of pregnant women's male partners $67.5 \%$ for the cases and 41.4 of the controls had 3 or more live children. The maximum number of live children among the enrolled study participants was 7 and 8 for the control group.

The study also revealed that $52.2 \%$ and $24.8 \%$ of the enrolled participants have completed primary school education for the control and study groups. On the other hand, $30.6 \%$ of cases have a partial secondary school education compared to $12.1 \%$ of the enrolled controls. In general, the study at least indicated that very few of the enrolled participants are on both education status extreme ends, no formal education or having higher education as shown in Table 1.

The study identified also the majority were in causal employment and self-employment, for the study group was $38.2 \%$ and $30.6 \%$ and for the control 
Table 1. Socio-Demographic Characteristics of the enrolled study participants.

\begin{tabular}{ccc}
\hline Parameter/predictor & $\begin{array}{c}\text { Intervention (Received SMS) } \\
\mathrm{n}=157(\%)\end{array}$ & $\begin{array}{c}\text { Control (No SMS) } \\
\mathrm{n}=157(\%)\end{array}$ \\
\hline Social demographic characteristics & & \\
Age, mean (range), completed years & $37.4(21-61)$ & $32.1(18-58)$ \\
$15-24$ & $5(3.2)$ & $33(21.0)$ \\
$25-34$ & $66(42.0)$ & $72(45.9)$ \\
$35-44$ & $50(31.8)$ & $32(20.4)$ \\
$45-54$ & $21(13.4)$ & $13(8.3)$ \\
$55+$ & $15(9.6)$ & $7(4.4)$ \\
Marital status & & $17(10.8)$ \\
Single & $6(3.8)$ & $131(83.5)$ \\
Married & $148(94.3)$ & $3(1.9)$ \\
Widowed & $0(0)$ & $6(3.8)$ \\
Separated & $3(1.9)$ & $8(5.1)$ \\
Education level & & $82(52.2)$ \\
No formal education & $4(2.5)$ & $30(19.2)$ \\
Primary education & $39(24.8)$ & $19(12.1)$ \\
Secondary education (Partially) & $48(30.6)$ & $6(3.8)$ \\
Secondary education & $24(15.3)$ & $9(5.7)$ \\
Post-secondary (Certificate) & $15(9.6)$ & $3(1.9)$ \\
Diploma & $18(11.5)$ & $98(62.4)$ \\
Higher education & $9(5.7)$ & $41(26.1)$ \\
Occupational status & & $15(9.6)$ \\
Self employed & $48(30.6)$ & $3(1.9)$ \\
Casual employment & $60(38.2)$ &
\end{tabular}

group was $62.4 \%$ and $26.1 \%$ respectively. In addition, the enrolled staff who were permanently employed by the Government was $29.3 \%$ for the study group compared to $9.6 \%$ in the control group.

The study found out that $90.2 \%$ of the enrolled pregnant women's male partners reported being informed on PMTCT services by health workers, $85.5 \%$ by informed by their friends and 59.4\% through radio spots before the SMS communication intervention. Also, 54.3\% reported to be informed by television spots, 23.2 through posters, and $14.7 \%$ through road shows as highlighted in Figure 1.

However, following SMS communication intervention 34\% of all enrolled male partners-participants from the study group preferred SMS communication on PMTCT services/HIV information compared to $30.5 \%$ who reported continued to prefer to be communicated by health care workers. Furthermore, $25.2 \%$ of enrolled pregnant women male partners preferred PMTCT/HIV communication by friends and no one preferred posters (Figure 2).

Awareness of HIV infection prevention is very important for people and especially the pregnant women's male partners for not performing HIV infection risk behaviors. This study revealed that awareness to the enrolled study group of pregnant women's male partners that condoms prevent HIV infection increased from $75.9 \%$ to $80.8 \%$ and from $70.1 \%$ to $75.5 \%$ for the control group after SMS communication intervention as shown in Table 2. 


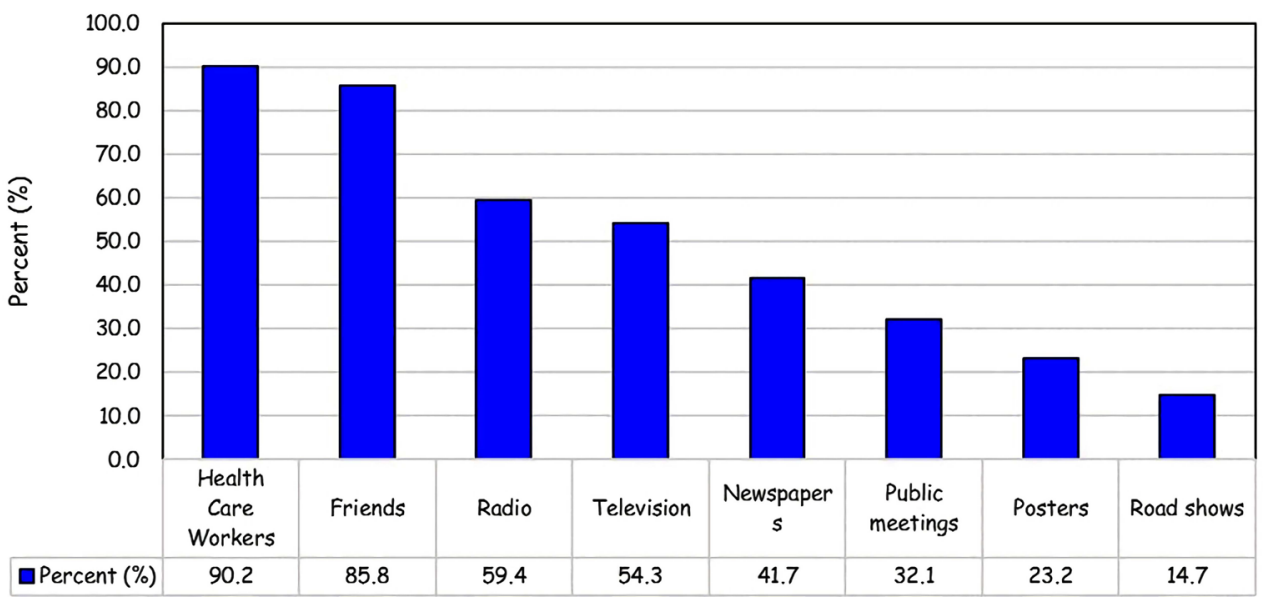

Figure 1. Reported PMTCT services information sources among enrolled pregnant women's male partners.

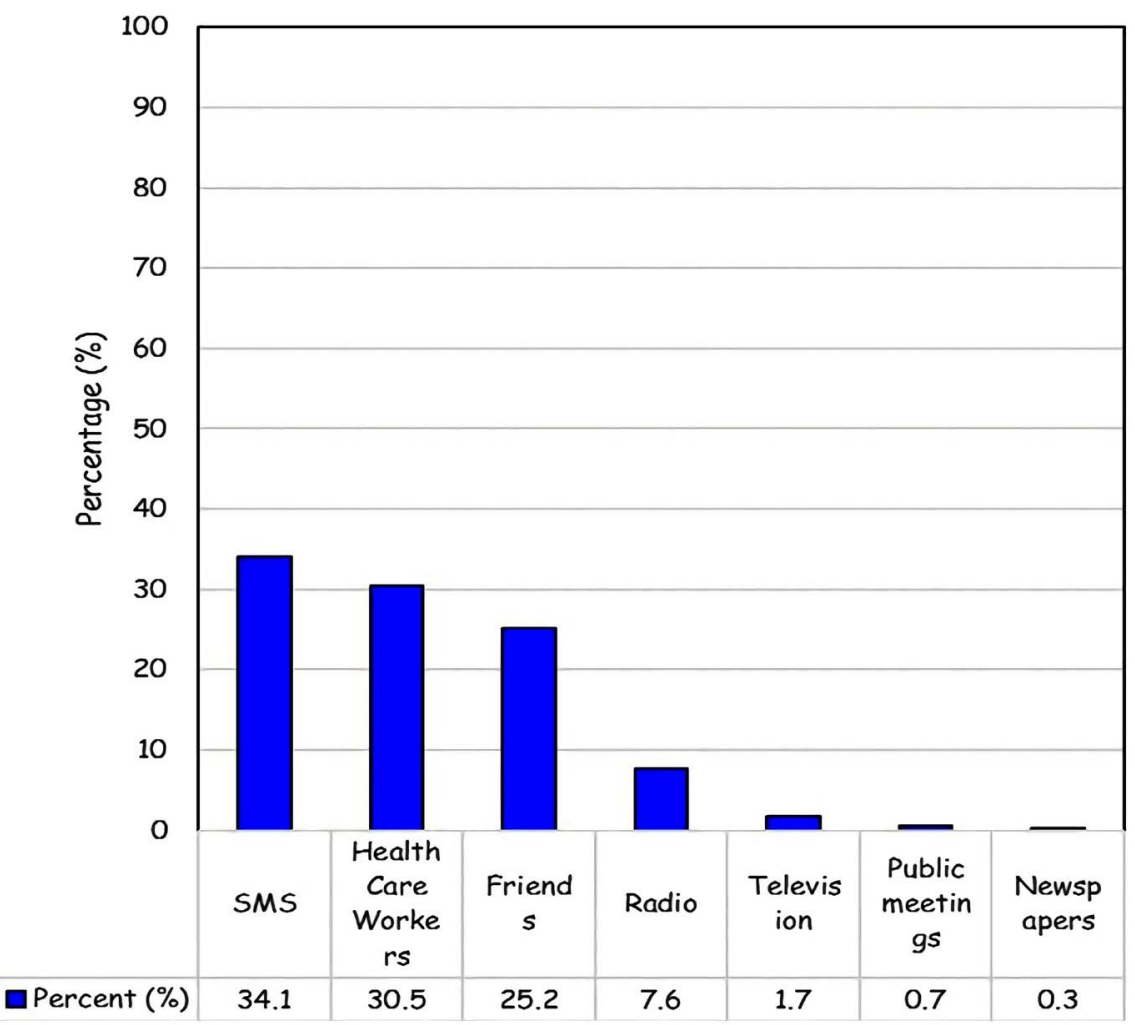

Figure 2. Reported preferred communication methods to the enrolled pregnant women's male partners.

Also, the understanding that HIV infected pregnant women can transmit the infection to their babies if they are not taking drugs increased from $56.9 \%$ to $70.6 \%$ and $48 \%$ to $57.4 \%$ for the cases (study group) and controls following the implementation of SMS communication. Not surprising also their knowledge that HIV infected pregnant women can transmit the infection in labor and breastfeeding increased from $55.4 \%$ to $73.3 \%$ to the enrolled study participants as cases and $47.5 \%$ to $61.8 \%$ for the cases. 
Table 2. The HIV infection awareness on specific study parameters among enrolled pregnant women's male partners before and after SMS communication intervention.

\begin{tabular}{|c|c|c|c|c|}
\hline \multirow[b]{2}{*}{ Variable } & \multicolumn{2}{|c|}{ Before Intervention } & \multicolumn{2}{|c|}{ After Intervention } \\
\hline & $\begin{array}{c}\text { Intervention } \\
\% \text { Yes }\end{array}$ & $\begin{array}{l}\text { Controls } \\
\% \text { Yes }\end{array}$ & $\begin{array}{c}\text { Intervention } \\
\text { \% Yes }\end{array}$ & $\begin{array}{c}\text { Controls } \\
\% \text { Yes }\end{array}$ \\
\hline $\begin{array}{l}\text { Does the use of condom during sex can } \\
\text { prevent HIV Mode of HIV transmission? }\end{array}$ & 75.9 & 70.1 & 80.8 & 75.5 \\
\hline $\begin{array}{l}\text { Do women with HIV infection can infect } \\
\text { their babies with HIV during pregnancy? }\end{array}$ & 56.9 & 48.0 & 70.6 & 57.4 \\
\hline $\begin{array}{l}\text { Do women with HIV infection can infect } \\
\text { their babies with HIV during labor? }\end{array}$ & 55.4 & 59.1 & 73.3 & 59.9 \\
\hline $\begin{array}{l}\text { Do women with HIV infection can infect } \\
\text { their babies with HIV through breastfeeding? }\end{array}$ & 47.5 & 54.8 & 61.8 & 60.3 \\
\hline $\begin{array}{l}\text { Are there any medicines from health facility } \\
\text { which HIV infected mothers can take during } \\
\text { pregnancy to prevent transmission of HIV } \\
\text { infection to their babies? }\end{array}$ & 53.6 & 61.9 & 66.7 & 60.6 \\
\hline $\begin{array}{l}\text { Are male partners testing for HIV important } \\
\text { during pregnancy? }\end{array}$ & 89.0 & 86.6 & 83.2 & 80.4 \\
\hline
\end{tabular}

The study found out that there was an increase in the awareness that there are ARV/PMTCT drugs in health facilities which when taken appropriately can prevent transmission of HIV infection from pregnant women to their babies increased from $53.6 \%$ to $66.7 \%$ after SMS communication only to the study group. For the importance of male testing during pregnancy, the understanding increased from $83.2 \%$ to $89 \%$ and from $80.4 \%$ to $86.6 \%$ for the study and control groups respectively. There was a statistical significance between the study and control group on the awareness that HIV infected mothers can transmit HIV infection to their babies after SMS communication with 13.2 percentage change, a $p$-value of 0.015 (95 C.I ranges $2.5 \%$ to $23.4 \%$ ). Also, there was a significant change between study and control after SMS communication on the fact that HIV infected pregnant women can infect their babies with HIV (if not taking PMTCT drugs) during labor with 13.4 percentage change between the groups, a $p$-value of 0.012 (95\% C.I ranges from 2.9 to $23.4 \%$ ).

The study indicated that before SMS communication to the enrolled pregnant women's male partners, $56.5 \%$ of the study group aged less than 35 years conducted HIV infection risk behavior compared to $32.7 \%$ from the control groups of the same age group. There is a significant variation for the two groups with 23.8 percentage change and a $p$-value of 0.002 (Table 3(a)). Furthermore, the enrolled pregnant women of married male partners from the study group (42.8\%) reported practicing more HIV infection risk behaviors compared to $30.9 \%$ of married men in the control group. This is not only an $11.9 \%$ variation but also with a significant change with a $p$-value of 0.045 . The other parameters in this study indicated a significant variability between the study and control group regarding practice HIV infection risk behaviors before SMS communication was 
Table 3. (a) Association between HIV Sexual practice and the exposure variables among pregnant women's male partners before SMS communication; (b) Association between HIV Sexual practice and the exposure variables among pregnant women's male partners after SMS communication; (c) Association between HIV Sexual practice, the exposure variables and relative risk among pregnant women's male partners after SMS communication.

(a)

\begin{tabular}{cccc}
\hline & $\begin{array}{c}\text { Study group (Cases) } \\
\text { Pof HIV infection risk } \\
\text { sexual acts }\end{array}$ & $\begin{array}{c}\text { Control group (Controls) } \\
\text { of HIV infection risk } \\
\text { sexual acts }\end{array}$ & P-value \\
\hline Age & & & \\
$<35$ years & $39 / 69(56.5)$ & $33 / 101(32.7)$ & 0.002 \\
$\geq 35$ years & $30 / 85(31.9)$ & $19 / 51(37.3)$ & 0.818 \\
Marital status & & & \\
Married & $62 / 145(42.8)$ & $39 / 126(30.9)$ & 0.045 \\
Unmarried & $7 / 9(77.8)$ & $13 / 26(50.0)$ & 0.147 \\
Live number of children & & & \\
- 2 & $25 / 49(51.0)$ & $30 / 88(34.1)$ & 0.053 \\
$>2$ & $44 / 105(41.9)$ & $22 / 64(34.4)$ & 0.330 \\
Educational level & & & \\
Primary or informal education & $17 / 41(41.5)$ & $17 / 85(20.0)$ & 0.011 \\
Secondary education & $30 / 71(42.2)$ & $24 / 49(49.0)$ & 0.467 \\
College & $22 / 42(52.4)$ & $11 / 18(61.1)$ & 0.533 \\
Occupational status & & & \\
Self employed & $18 / 47(38.3)$ & $28 / 94(29.8)$ & 0.310 \\
Casual employment & $25 / 58(43.1)$ & $13 / 40(32.5)$ & 0.290 \\
Permanent employed & $26 / 49(53.1)$ & $11 / 18(61.1)$ & 0.557 \\
Partners in the past six & & & \\
months, no & & & 0.036 \\
1 & $34 / 83(41.0)$ & $29 / 109(26.6)$ & 0.664 \\
$\geq 2$ & $35 / 71(49.3)$ & $23 / 43(53.5)$ &
\end{tabular}

(b)

\begin{tabular}{|c|c|c|c|}
\hline Parameter(s) & $\begin{array}{l}\text { Study group (Cases) } \\
\% \text { of HIV infection risk } \\
\text { sexual acts }\end{array}$ & $\begin{array}{l}\text { Control group (Controls) } \\
\% \text { of HIV infection risk } \\
\text { sexual acts }\end{array}$ & $P$-value \\
\hline \multicolumn{4}{|l|}{ Age } \\
\hline$<35$ years & $1 / 66(1.5)$ & 18/91 (19.8) & 0.001 \\
\hline$\geq 35$ years & $1 / 79(1.3)$ & $18 / 49(36.7)$ & $<0.001$ \\
\hline \multicolumn{4}{|l|}{ Marital status } \\
\hline Married & $1 / 125(0.80)$ & $33 / 124(26.6)$ & $<0.001$ \\
\hline Unmarried & $1 / 20(5.0)$ & $3 / 16(18.7)$ & 0.192 \\
\hline \multicolumn{4}{|l|}{ Live number of children } \\
\hline $0-2$ & $0 / 60(0.0)$ & 9/71 (12.7) & 0.004 \\
\hline$>2$ & $2 / 85(2.4)$ & $27 / 69(39.1)$ & $<0.001$ \\
\hline \multicolumn{4}{|l|}{ Educational level } \\
\hline Primary or informal education & $1 / 83(1.2)$ & $4 / 28(14.3)$ & 0.004 \\
\hline Secondary education & $1 / 40(2.5)$ & $22 / 77(28.6)$ & 0.001 \\
\hline College & $0 / 22(0.0)$ & $10 / 35(28.6)$ & 0.006 \\
\hline \multicolumn{4}{|l|}{ Occupational status } \\
\hline Self employed & $2 / 96(2.1)$ & $7 / 40(17.5)$ & 0.001 \\
\hline Casual employment & $0 / 22(0.0)$ & $16 / 54(29.6)$ & 0.004 \\
\hline Permanent employed & $0 / 27(0.0)$ & $13 / 46(28.3)$ & 0.002 \\
\hline \multicolumn{4}{|l|}{$\begin{array}{l}\text { Partners in the past six months, } \\
\text { no }\end{array}$} \\
\hline 1 & $0 / 90(0.0)$ & $17 / 84(20.2)$ & $<0.001$ \\
\hline$\geq 2$ & $2 / 55(3.6)$ & $19 / 56(33.9)$ & $<0.001$ \\
\hline
\end{tabular}


(c)

\begin{tabular}{|c|c|c|c|c|}
\hline \multirow[b]{2}{*}{ Predictor } & \multicolumn{2}{|c|}{$\begin{array}{l}\text { Percentage of performing } \\
\text { HIV risk practices }\end{array}$} & \multirow{2}{*}{$\begin{array}{c}{ }^{*} \text { Relative Risk (RR) } \\
(95 \% \mathrm{CI})\end{array}$} & \multirow[b]{2}{*}{$\dagger P$-value } \\
\hline & $\begin{array}{l}\text { Study group } \\
\quad \text { (Cases) } \\
(\mathrm{n}=145)\end{array}$ & $\begin{array}{l}\text { Control group } \\
\text { (Controls) } \\
(\mathrm{n}=140)\end{array}$ & & \\
\hline \multicolumn{5}{|l|}{ Age } \\
\hline$<35$ years & 1.5 & 19.8 & $0.11(0.02-0.76)$ & 0.0005 \\
\hline$\geq 35$ years & 1.3 & 36.7 & $0.07(0.01-0.50)$ & $<0.0001$ \\
\hline \multicolumn{5}{|l|}{ Marital status } \\
\hline Married & 0.8 & 26.6 & $0.05(0.01-0.35)$ & $<0.0001$ \\
\hline Unmarried & 5.0 & 18.7 & $0.42(0.08-2.35)$ & 0.0002 \\
\hline \multicolumn{5}{|l|}{ Live number of children } \\
\hline $0-2$ & 0.0 & 12.7 & $0.0(0.00-0.00)$ & 0.3029 \\
\hline$>2$ & 2.4 & 39.1 & $0.1(0.03-0.40)$ & $<0.0001$ \\
\hline \multicolumn{5}{|l|}{ Educational level } \\
\hline Primary or informal education & 1.2 & 14.3 & $0.26(0.04-1.50)$ & 0.0039 \\
\hline Secondary education & 2.5 & 28.6 & $0.10(0.02-0.72)$ & 0.0008 \\
\hline College & 0.0 & 28.6 & $0.00(0.00-0.00)$ & 0.0058 \\
\hline \multicolumn{5}{|l|}{ Occupational status } \\
\hline Self employed & 2.1 & 17.5 & $0.30(0.09-1.02)$ & 0.0010 \\
\hline Casual employment & 0.0 & 0.0 & $0.00(0.00-0.00)$ & 0.0041 \\
\hline Permanent employed & 0.0 & 0.0 & $0.00(0.00-0.00)$ & 0.0023 \\
\hline \multicolumn{5}{|l|}{ Partners in the past six months } \\
\hline 1 & 0.0 & 20.2 & $0.00(0.00-0.00)$ & $<0.0001$ \\
\hline$\geq 2$ & 3.6 & 33.9 & $0.16(0.04-0.61)$ & $<0.0001$ \\
\hline
\end{tabular}

${ }^{\dagger}$ Two-sided $p$ value for $\mathrm{Z}$ statistic of the difference in probabilities.

the men with less than 2 live children, men completed with primary school or informal education, and men with 1 concurrent sexual partner within 6 months prior to the study (Table 3(a)).

Following the implementation of SMS communication to the study group on 5 key messages as explained in the methodology, men in the study group for all age groups categories, were less likely to practice HIV infection risk behavior compared to control group with a significant change of $p$-value of 0.001 for the under 35 years and less than 0.001 for men above 35 years. The study also observed variation in all categories except married men categories for the study group, there was a significant reduction (a $p$-value of less than 0.05 ) for performing HIV infection risk behaviors, such categories of the study were the number of live children, education levels, occupational status, and partners in the six months before the study (Table 3(b)).

The study also identified in Table 3(c) that the risk of men aged less than 35 years in the study group was reduced with RR of 0.11 (95\% C.I ranges from 0.02 to 0.76$)$ compared to the controls. The risk of unmarried men was also lower with RR of 0.42 (95\% C.I. ranges from 0.08 to 2.35) compared to the controls. The risk for the study group was also reduced to men with primary or informal education with RR of 0.26 (95\% C.I. ranges from 0.04 to 1.50 ), with secondary education with RR of 0.10 ( $95 \%$ C.I. ranges from 0.02 to 0.72 ), self-employed 0.30 (95\% C.I. ranges from 0.09 to 1.02 ) and with more than 1 concurrent partner with RR 0.16 (95\% C.I. ranges from 0.04 to 0.61 ). 
The results of the in-depth interview from the 42 key informants indicated that $60 \%$ of the interviewed key informants who are also health workers believed that the awareness that, male partners can participate in PMTCT and stop HIV infection risk behaviors can be delivered through mass media. Also, 24\% of key informants believed that SMS communication is the best communication platform as it was used in this study. The other options were youth-friendly services and appropriate use of HIV related school health programs as shown in Figure 3 below.

\section{Discussion}

The results from the study indicate age variability between the study and control group as shown and the median age was 35 years and 44 years for the study and control group respectively. In making consideration of HIV epidemiology in Tanzania, the age group with a high prevalence of $8.4 \%$ is the age group of 40 to 44 years of men compared to all other age groups (URT, 2018). In this study, this age group is the subset of the age group of 35 to 44 years where the majority are in the study group (31.8\%) compared to $20.4 \%$ of the control group.

Following SMS communication intervention, men from the study group were less likely to practice HIV infection sexual risk behavior compared to the control

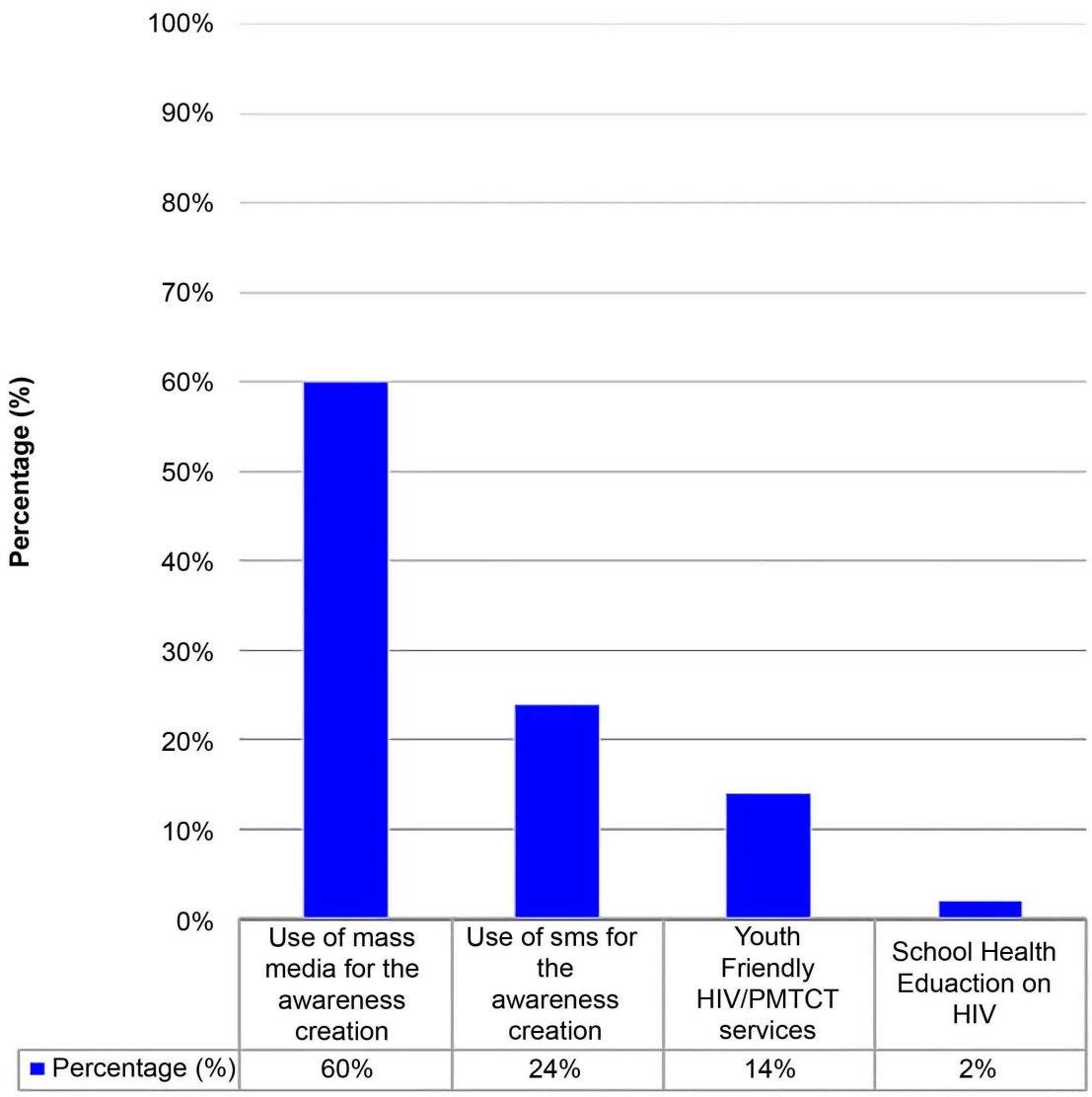

Figure 3. Reported suggestions from the study key informants on perceived methods for the increased awareness of pregnant women's male partner. 
group. The two age groups below 35 years showed an $18.3 \%$ change and a $35.4 \%$ change for those who were over 35 years old. The difference was tested and found to be statistically significant with a $p$-value of 0.001 (relative risk of 0.11 ) and less than 0.001 (relative risk of 0.07 ) respectively at a $95 \%$ confidence interval. This indicates that the SMS communication was very effective for all age groups of the enrolled male partners of pregnancy women. Again, because majority of the study group were the age group with high HIV prevalence in that regards, the study may be had contributed to not only HIV infection risk behaviors but also new HIV infection to pregnant women and their babies. The findings are like the results of a study done in the Northern part of Tanzania which enrolled 1333 couples where the HIV sero-discordant relationship was associated with 35 - 45 years age category for enrolled men and women which is the same age group in this study (Ngilangwa, Ochako, Mboya, Noronha, \& Mgomella, 2015). The findings from the study indicate that if the SMS communication could be implemented in the rest of districts in Tanzania especially the Tabora Region, it will accelerate both the milestones for the PMTCT elimination and HIV infection reduction goals.

It was also indicated that there is the likelihood of unmarried male partners in the study group to practice HIV risk behavior compared to unmarried male partners in the control group the value of $p$ was less than 0.001 ( $95 \%$ C.I) before implementing SMS communication. The study also indicated that there is a reduction of risk for both unmarried and married men in the study group following SMS communication in the study group compared to controls with a relative risk of 0.42 for unmarried and 0.05 and they are all statically significant. The finding is similar to a study conducted in Arusha and Kilimanjaro which picked up unmarried, alcohol consumption and living in urban areas (Arusha) to be among the risk for performing HIV infection sexual risk behavior (Ngilangwa et al., 2015).

In addition, the male partners with 2 or more live children in the study group were less likely to practice HIV sexual risk behaviors $p$-value < 0.001 (95\% C.I). This may be as people are becoming more responsible are also fearing to practice HIV infection sexual risk behavior. Similar findings were reported in South Africa when men with children were not avoiding performing HIV infection risk behavior but also if they were diagnosed HIV positive were likely to take ARV to prevent the sufferings of their children (Koo, Makin, \& Forsyth, 2013).

The study also indicates the variability of health workers believes and clients' needs in terms of where to receive health information. Even though a large-scale study may provide more information, however, the study highlighted how simple common interventions can be well accepted by community and change to healthy behaviors and practices. Sexual practices and behaviors contribute to HIV new infection and study opened eyes that interventions to prevent mothers and children HIV infection may be well addressed if male partners (formal husband and concurrent sexual partners) are also addressed similarly to studies results in Northern Tanzania and in Kenya (Kaiser et al., 2011; Ngilangwa et al., 2015). 


\section{Conclusion}

The study results indicated a clear effect of SMS communication intervention in reducing HIV sexual risk behavior in pregnant women male partners especially in the study group which was tested and found out to be statistically significant. The study also suggests an improved approach for awareness creation from traditional methods of mass media and posters. We also suggest that health promotion guidelines for PMTCT and HIV/AIDs should be reviewed to include adaptive innovation and strategies like SMS communications in the national PMTCT and HIV/AIDs programs.

\section{Acknowledgements}

We acknowledge efforts made by Mr. Pascal Matagi, Richard Robert, Bahati Charles, Khalef Salim, Mohammed Mohamed, and Gloria Ngowi for the 13 months rally of day and night data collection and entry with the deployment of innovative procedures. Special acknowledgment to Mr. Jethro Chakauya and David Kayabu for statistical consultations.

\section{Conflicts of Interest}

The authors declare no conflicts of interest regarding the publication of this paper.

\section{References}

Agnarson, A. M., Strömdahl, S., Levira, F., Masanja, H., \& Thorson, A. E. (2015). Female-Driven Multiple Concurrent Sexual Partnership Systems in a Rural Part of a Southern Tanzanian Province. PLOS ONE, 10, e0145297. https://doi.org/10.1371/journal.pone.0145297

Ajzen, I. (1985). From Intentions to Actions: A Theory of Planned Behavior. In J. Kuhl, \& J. Beckmann (Eds.), Action Control (pp. 11-39). Berlin, Heidelberg: Springer. https://doi.org/10.1007/978-3-642-69746-3_2

Ajzen, I. (2011). The Theory of Planned Behaviour: Reactions and Reflections. Psychology and Health, 26, 1113-1127. https://doi.org/10.1080/08870446.2011.613995

Bain, L. E., Nkoke, C., \& Noubiap, J. J. N. (2017). UNAIDS 90-90-90 Targets to End the AIDS Epidemic by 2020 Are Not Realistic: Comment on "Can the UNAIDS 90-90-90 Target Be Achieved? A Systematic Analysis of National HIV Treatment Cascades". BMJ Global Health, 2, e000227. https://doi.org/10.1136/bmjgh-2016-000227

CDC (2014). Integrated Guidance for Developing Epidemiologic Profiles: HIV Prevention and Ryan White HIV/AIDS Programs Planning.

Faghanipour, S., Hajikazemi, E., Nikpour, S., al-Sadat Shariatpanahi, S., \& Hosseini, A. F. (2013). Mobile Phone Short Message Service (SMS) for Weight Management in Iranian Overweight and Obese Women: A Pilot Study. International Journal of Telemedicine and Applications, 2013, Article ID: 785654. https://doi.org/10.1155/2013/785654

Fearon, E., Wiggins, R. D., Pettifor, A. E., MacPhail, C., Kahn, K., Selin, A. et al. (2019). Friendships among Young South African Women, Sexual Behaviours and Connections to Sexual Partners (HPTN 068). AIDS and Behavior, 23, 1471-1483.

https://doi.org/10.1007/s10461-019-02406-x 
Fox, N., Hunn, A., \& Mathers, N. (2009). Sampling and Sample Size Calculation. The NIHR Research Design Service for the East Midlands, MHS.

Hurling, R., Catt, M., De Boni, M., Fairley, B. W., Hurst, T., Murray, P. et al. (2007). Using Internet and Mobile Phone Technology to Deliver an Automated Physical Activity Program: Randomized Controlled Trial. Journal of Medical Internet Research, 9, e7. https://doi.org/10.2196/jmir.9.2.e7

Jewkes, R., Dunkle, K., Nduna, M., Levin, J., Jama, N., Khuzwayo, N. et al. (2006). Factors Associated with HIV Sero-Status in Young Rural South African Women: Connections between Intimate Partner Violence and HIV. International Journal of Epidemiology, 35, 1461-1468. https://doi.org/10.1093/ije/dyl218

Kaiser, R., Bunnell, R., Hightower, A., Kim, A. A., Cherutich, P., Mwangi, M. et al. (2011). Factors Associated with HIV Infection in Married or Cohabitating Couples in Kenya: Results from a Nationally Representative Study. PLoS ONE, 6, e17842. https://doi.org/10.1371/journal.pone.0017842

Kapesa, A., Basinda, N., Nyanza, E. C., Mushi, M. F., Jahanpour, O., \& Ngallaba, S. E. (2018). Prevalence of HIV Infection and Uptake of HIV/AIDS Services among Fisherfolk in Landing Islands of Lake Victoria, North Western Tanzania. BMC Health Services Research 18, Article No. 980. https://doi.org/10.1186/s12913-018-3784-4

Kasenga, F. (2010). Making It Happen: Prevention of Mother to Child Transmission of HIV in Rural Malawi. Global Health Action, 3, Article 1882. https://doi.org/10.3402/gha.v3i0.1882

Kashitala, J., Nyambe, N., Mwalo, S., Musamba, J., Chishinga, N., Kasonde, P. et al. (2015). Is Male Involvement in ANC and PMTCT Associated with Increased Facility-Based Obstetric Delivery in Pregnant Women? African Journal of Reproductive Health, 19, 117-124.

Koo, K., Makin, J. D., \& Forsyth, B. W. C. (2013). Barriers to Male-Partner Participation in Programs to Prevent Mother-to-Child HIV Transmission in South Africa. AIDS Education and Prevention, 25, 14-24. https://doi.org/10.1521/aeap.2013.25.1.14

Maheu-Giroux, M., Vesga, J. F., Diabate, S., Alary, M., Baral, S., Diouf, D., \& Boily, M. (2017). Population-Level Impact of an Accelerated HIV Response Plan to Reach the UNAIDS 90-90-90 Target in Côte d'Ivoire: Insights from Mathematical Modeling. PLoS Medicine, 14, e1002321. https://doi.org/10.1371/journal.pmed.1002321

Matiko, E., Khatib, A., Khalid, F., Welty, S., Said, C., Ali, A. et al. (2015). HIV Prevalence and Risk Behaviors among People Who Inject Drugs in Two Serial Cross-Sectional Respondent-Driven Sampling Surveys, Zanzibar 2007 and 2012. AIDS and Behavior, 19, 36-45. https://doi.org/10.1007/s10461-014-0929-2

Mmbaga, E. J., Kishimba, R. S., Mohammed, A. A., \& Elias, M. (2017). Male Partner Involvement in the Prevention of Mother to Child Transmission of HIV Infection in Mwanza Region, Tanzania. Pan African Medical Journal, 27, 90.

https://doi.org/10.11604/pamj.2017.27.90.8901

MoHCDEC (2018). Ministry of Health, Community Development, Gender, Elderly and Children National Adolescent Health and Development Strategy 2018-2022.

http://www.mcdgc.go.tz/index.php/mcdgc/aboutus/minister_minister_of_community_ development_gender_and_children/

Moses, A. E., Chama, C., Udo, S. M., \& Omotora, B. A. (2009). Knowledge, Attitude and Practice of Ante-Natal Attendees toward Prevention of Mother to Child Transmission (PMTCT) of HIV Infection in a Tertiary Health Facility, Northeast-Nigeria. East African Journal of Public Health, 6, 128-135.

Ngilangwa, D. P., Ochako, R., Mboya, B. A., Noronha, R. H., \& Mgomella, G. S. (2015). 
Prevalence and Predictors of HIV Sero-Discordance among Cohabiting Couples Tested in Northern Tanzania. The Pan African Medical Journal, 22, 275.

https://doi.org/10.11604/pamj.2015.22.275.5961

Shayo, E. H., Kalinga, A. A., Senkoro, K. P., Msovela, J., Mgina, E. J., Shija, A. E. et al. (2017). Prevalence and Risk Factors Associated with Female Anal Sex in the Context of HIV/AIDS in the Selected Districts of Tanzania. BMC Research Notes, 10, Article No. 140. https://doi.org/10.1186/s13104-017-2452-9

Shelton, J. D. (2009). Why Multiple Sexual Partners? The Lancet, 374, 367-369. https://doi.org/10.1016/S0140-6736(09)61399-4

Shey Nsagha, D., Edie Halle-Ekane, G., Shei Nfor, C., Ngowe Ngowe, M., \& Tatchwanglie Nasah, B. (2014). The Role of the Male Partner in the Prevention of Mother to Child Transmission of HIV in Cameroon. American Journal of Epidemiology and Infectious Disease, 2, 52-59. https://doi.org/10.12691/ajeid-2-2-1

UN (1989). A Guide to General Comment 7: Implementing Child Rights in Early Childhood. 2006 Bernard van Leer Foundation, The Hague. https://www.unicef.org/earlychildhood/files/Guide_to_GC7.pdf

UNAIDS (2016). The Prevention Gap Report (Vol. 83).

UNAIDS (2019). 2018 Global HIV Statistics. https://www.unaids.org/sites/default/files/media_asset/UNAIDS_FactSheet_en.pdf

URT (2017). Tanzania in Figures 2016. Dar es salaam, Tanzania: National Bureau of Statistics. https://nbs.go.tz/nbs/takwimu/references/Tanzania_in_Figures_2016.pdf

URT (2018). Tanzania HIV Impact Survey (THIS) 2016-2017. In Tanzania HIV Impact Survey (THIS) 2016-2017. Dar es Salaam, Tanzania: National Bureau of Statistics. http://www.nbs.go.tz/nbs/takwimu/this2016-17/Tanzania_SummarySheet_English.pdf

WHO (2018). mHealth, Use of Appropriate Digital Technologies for Public Health. In Seventy-First World Health Assembly-Provisional Agenda Item 12.4 (A71/20) (Vol. 28, p. 26). 